\title{
Study of Molybdenum Trioxide as a P-Type Dopant in Organic Semiconductors: The Influence of Density of Gap States on Their N-/P- Type Characteristics
}

\author{
Jingqiu Zhanga , Shainan Zhu ${ }^{\mathrm{b}}$, Lintai Shang ${ }^{\mathrm{c}}$, Jinpeng Yang ${ }^{\mathrm{d}, ~}$ * \\ School of Physical Science and Technology, Yangzhou University, Jiangsu 225009, China \\ a292532076@qq.com, b1600202862@qq.com, c1216538590@qq.com, dyangjp@yzu.edu.cn
}

Keywords: organic semiconductors, molecular doping, density of gap states, conductivity, $\mathrm{MoO}_{3}$.

\begin{abstract}
. we studied the mechanism of original n- and p-type "intrinsic" organic films 8-Hydroxyquinoline aluminum ( $\mathrm{Alq}_{3}$ ) and $\mathrm{N}, \mathrm{N}$ '-bis-1-naphthyl-N, N'-diphenyl-1, 1'-biphenyl-4, 4'-diamine (NPB) via using molybdenum trioxide $\left(\mathrm{MoO}_{3}\right)$ as a p-type dopant. It is found that the conductivities extracted from "holes-only" devices both for $\mathrm{Alq}_{3}$ and NPB films are improved as a function of doping molar ratio (MR) of $\mathrm{MoO}_{3}$. However, the differences of change of conductivities in NPB films and $\mathrm{Alq}_{3}$ films after doping can be found, where (1) a rapid increase of conductivity in $\mathrm{Alq}_{3}$ with slope $S>1$ is shown in the entire MR range; (2) in NPB films, the conductivity changes with a slope of $S>1$ can be found in the low doping region $(M R<\sim 0.04)$ and a slope of $\sim 1$ can be found with $M R>\sim 0.04$. According to these observation, we proposed that different distributions of occupied and unoccupied DOGS in energy gap of organic films is the origin of "intrinsic" $n-/ p$ - type organic films, and therefore can be passivated differently via $\mathrm{MoO}_{3}$. These findings suggest the effective way for improving free carriers concentrations by reducing DOGS in organic films.
\end{abstract}

\section{Introduction}

Organic semiconducting materials have been widely utilized into the device field due to their practical applications in organic light emitting diodes (OLED) [1, 2], organic photovoltaics (OPV) [3, $4]$ and organic field effect transistors (OFET) [5, 6, 7]. The main advantages of organic films are low cost, mechanically flexible and available for large area fabrication. [8, 9] Unlike inorganic semiconductors which are functionalized commonly by using different dopants (e.g. donor atoms for $\mathrm{n}$ type semiconductor, or acceptor atoms for $\mathrm{p}$ type semiconductor), organic semiconductor materials always directly demonstrate their own "intrinsic" properties with either given an n-type or p-type without using doping. For example, fullerene $\left(\mathrm{C}_{60}\right)$ is commonly thought as an n-type material [10]; on the other hand, Copper phthalocyanine $(\mathrm{CuPc})$ is considered as a p-type material [11]. To further improve organic device performance, doping in organic films is also widely used for lowering injection barriers for charges injection $[12,13]$ and improving films conductivities through the increase of carriers concentration $[14,15]$. In recent years, transition metal oxides such as molybdenum trioxide $\left(\mathrm{MoO}_{3}\right)$, tungsten trioxide $\left(\mathrm{WO}_{3}\right)$ have been widely used as effective dopants for realizing p-type organic films in organic devices due to their high work functions (WFs) $(>6 \mathrm{eV}$ ) and larger electron affinity (e.g. $6.4 \mathrm{eV}$ for $\mathrm{MoO}_{3}$ ), which can easily induce charge transfer from organic molecules with their highest occupied molecular orbital (HOMO) to conduction band of transition metal oxides and therefore result in increasing of hole concentration in organic films. [16, 17] Recent studies even show that in $\mathrm{C}_{60}$ films, doping with $\mathrm{MoO}_{3}$ can realize the transition of $\mathrm{C}_{60}$ films from n-type to $\mathrm{p}$-type due to the formation of $\mathrm{C}_{60}$ cations induced by complete charge transfer, $[16,18]$ which demonstrates the behavior similar to inorganic semiconductors. However, $\mathrm{C}_{60}$ is a very limit case that one type of organic films can both realize $\mathrm{n}$-/p-type characteristics via doping. In most organic molecules, their own "intrinsic" properties of n-/p- types even with doping cannot make the transition (e.g. change from n-type to p-type or p-type to n-type). They are commonly considered to be only favorable for one type of carriers transport. However, the origin of such "intrinsic" $n-/ p$ - type property in organic films and their doping mechanism is only limit studied. [19, 20] 
In this paper, we studied the mechanism of original $\mathrm{n}$ - and $\mathrm{p}$ - type "intrinsic" organic films 8-Hydroxyquinoline aluminum ( $\mathrm{Alq}_{3}$ ) and $\mathrm{N}, \mathrm{N}$-bis-1-naphthyl-N, N'-diphenyl-1, 1'-biphenyl-4, 4'-diamine (NPB) via using $\mathrm{MoO}_{3}$ as a p-type dopant. It is found that conductivities of organic films both for $\mathrm{Alq}_{3}$ and NPB films are improved with increasing of the molecular doping molar ratio (MR) of $\mathrm{MoO}_{3}$. Moreover, the transition of change of conductivities in NPB films as a function of molecular doping ratio is also found, in which a slope of $\mathrm{S}>1$ can be found in the low doping region (MR< 0.04) and a slope of $\mathrm{S} \sim 1$ can be found with $\mathrm{MR}>\sim 0.04$. On the other hand, doping $\mathrm{MoO}_{3}$ into $\mathrm{Alq}_{3}$ films only shows a slope $S>1$ in the entire doping region. These findings can be well explained from their "intrinsic" n-/p- types originated from different distributions of occupied and unoccupied density of gap states (DOGS) in organic films. In p-type NPB films, occupied DOGS is smaller than unoccupied DOGS, which can be easily removed via low doping of $\mathrm{MoO}_{3}$, results in the larger increase of conductivities. On the contrary, in n-type $\mathrm{Alq}_{3}$ films, occupied DOGS is much larger than unoccupied DOGS, which cannot be easily removed even via high level doping, therefore given a larger slope $S>1$.

\section{Result and discussion}

$\mathrm{MoO}_{3}(99.8 \%)$ were bought from Sigma-Aldrich and used without purification. NPB and $\mathrm{Alq}_{3}$ were both bought from Luminescence Technology Corp. and used with three times further purification. The molecular structures of NPB and $\mathrm{Alq}_{3}$ were given in Figure 1 (a). All the devices were fabricated on patterned indium tin oxide (ITO)-coated glass substrates with a sheet resistance of $20 \Omega \mathrm{sq}^{-1}$. Prior to film deposition, the ITO glass substrates were sonicated in acetone, alcohol, deionized water for each 15 minutes, and finally dried before using. All the organic and inorganic films were thermally deposited within a high vacuum deposition system at a base pressure of $<1 \times 10^{-4} \mathrm{~Pa}$ through a shadow mask. "Holes only" device structures were $\mathrm{ITO} / \mathrm{MoO}_{3}(5 \mathrm{~nm}) /$ different organic layers $(60 \mathrm{~nm}) / \mathrm{MoO}_{3}$ $(5 \mathrm{~nm}) / \mathrm{Al}(100 \mathrm{~nm})$, in which $5 \mathrm{~nm}-\mathrm{MoO}_{3}$ is used in both sides for blocking the electrons injection and minimal injection barriers for holes (Their energy diagram with respect to vacuum level can be found in Figure 1(b) [21, 22]). The effective area of devices is $0.1 \mathrm{~cm}^{2}$. Deposition rates of different layers were monitored with quartz-crystal monitors and controlled to be $1-2 \AA \mathrm{s}^{-1}$. The doping of organic layers was performed by thermal co-evaporation from individual sources, which were controlled via one quartz-crystal monitor. The current density-voltage characteristics of the corresponding devices were measured with Agilent B1500A Semiconductor Device Analyze power source in air ambience at room temperature. Absorption spectrum were measured by UV-vis-near infrared absorption spectroscopy (Cary 5000). The molar ratio (MR) in the $\mathrm{MoO}_{3}$-doped-NPB (or $\mathrm{Alq}_{3}$ ) film was defined as the number of $\left(\mathrm{MoO}_{3}\right)_{3}$ clusters to NPB (or Alq ${ }_{3}$ ) molecules. Positive voltage was defined as the ITO electrode applied positively.

(a)

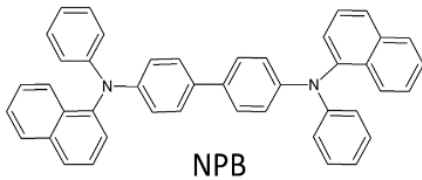

NPB

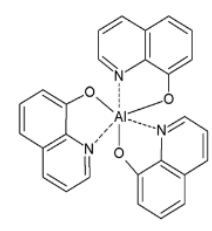

$\mathrm{Alq}_{3}$ (b)
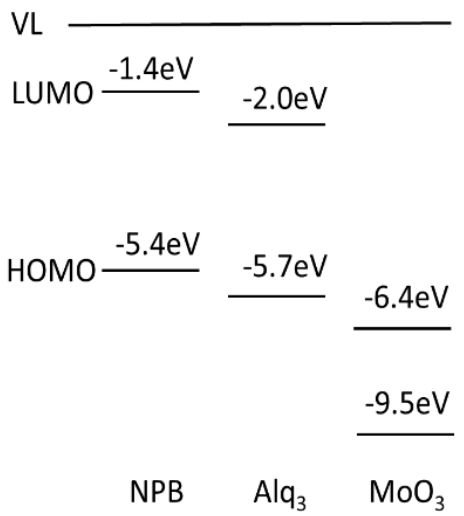

Figure 1. (a) Molecular structures of NPB $\left(\mathrm{C}_{44} \mathrm{H}_{32} \mathrm{~N}_{2}\right)$ and $\mathrm{Alq}_{3}\left(\mathrm{C}_{27} \mathrm{H}_{18} \mathrm{AlN}_{3} \mathrm{O}_{3}\right)$; (b) Energy band diagram of HOMOs and LUMOs in NPB, $\mathrm{Alq}_{3}$ and $\mathrm{MoO}_{3}$ with respect to vacuum level Their HOMO and LUMO values are given from published literatures. [21, 22] 
(a)

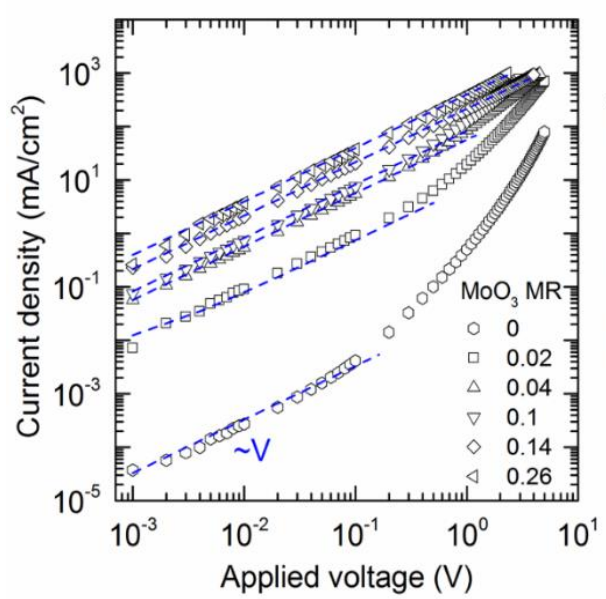

(b)

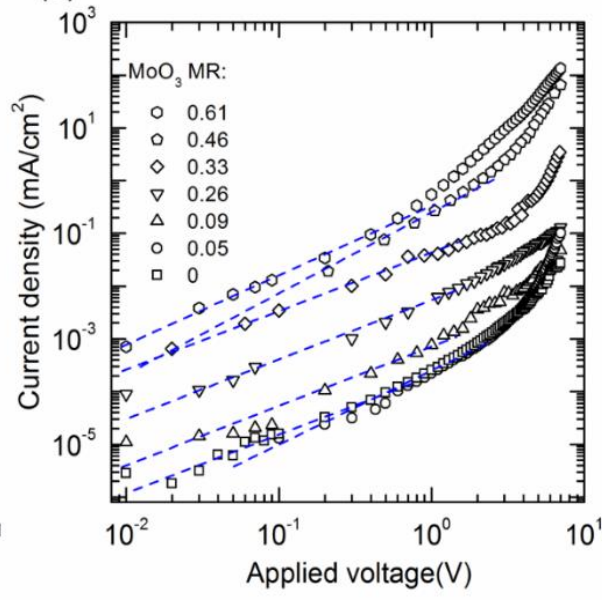

Figure 2. Logarithmic plotting of Current density-applied voltage curves of devices with layer structures ITO/ $\mathrm{MoO}_{3}(5 \mathrm{~nm}) /$ different organic layers $(60 \mathrm{~nm}) / \mathrm{MoO}_{3}(5 \mathrm{~nm}) / \mathrm{Al}(100 \mathrm{~nm})$, in which (a) $\mathrm{MoO}_{3}$ doping to NPB with different molar doping ratios (MR). (b) $\mathrm{MoO}_{3}$ doping to $\mathrm{Alq}_{3}$ with different

MR. The dash lines are given with linear fitting at low applied voltage regions.

Figure 2 shows the logarithmic plotting of current density as a function of applied voltage in different MR of $\mathrm{MoO}_{3}$ doped "hole-only" organic devices with (a) in NPB films and (b) in Alq 3 films. It is clearly found that the current density at a given voltage increases with $\mathrm{MR}$ of $\mathrm{MoO}_{3}$ both in NPB films and $\mathrm{Alq}_{3}$ films. Moreover, the increase of current density is up to five orders of magnitude at the highest MR investigated here in NPB films and three orders of magnitude at the highest MR in $\mathrm{Alq}_{3}$ films. For example, with applied voltage of $0.05 \mathrm{~V}$, the current density is $0.0014 \mathrm{~mA} / \mathrm{cm}^{2}$ (for pristine $\mathrm{NPB}$ ) and $21.04 \mathrm{~mA} / \mathrm{cm}^{2}$ (for $\mathrm{MR}=0.26 \mathrm{MoO}_{3}$-doped-NPB), while the current density is only $5.6 \times 10^{-6} \mathrm{~mA} / \mathrm{cm}^{2}$ (for pristine $\mathrm{Alq}_{3}$ ) and $6.7 \times 10^{-3} \mathrm{~mA} / \mathrm{cm}^{2}$ (for $\mathrm{MR}=0.61 \mathrm{MoO}_{3}$-doped-Alq ${ }_{3}$ ), respectively. Considering NPB is commonly thought as a p-type semiconductor material with holes concentration larger than electrons, which expects the larger increasing of current density at higher $\mathrm{MoO}_{3}$ doping ratios and thus a linear relation of current density-applied voltage is expected to occur (e.g. for $\mathrm{MR}=0.14$ and 0.26 in Figure 1(a)). On the other hand, $\mathrm{Alq}_{3}$ is considered as an n-type semiconductor material with low holes concentration, which should also expect a change of n-type to p-type at a certain high $\mathrm{MoO}_{3}$ doping ratios based on the theory of inorganic semiconductors. Thus a linear current density-voltage curve should be found in these "holes-only" devices. However, even at a higher $\mathrm{MR}$ of $\mathrm{MoO}_{3}(\mathrm{MR}=0.61)$, a linear relation only can be obtained at lower applied voltages, while change at high applied voltages, indicate the low holes concentration in high $\mathrm{MoO}_{3}$-doped-Alq ${ }_{3}$ films.
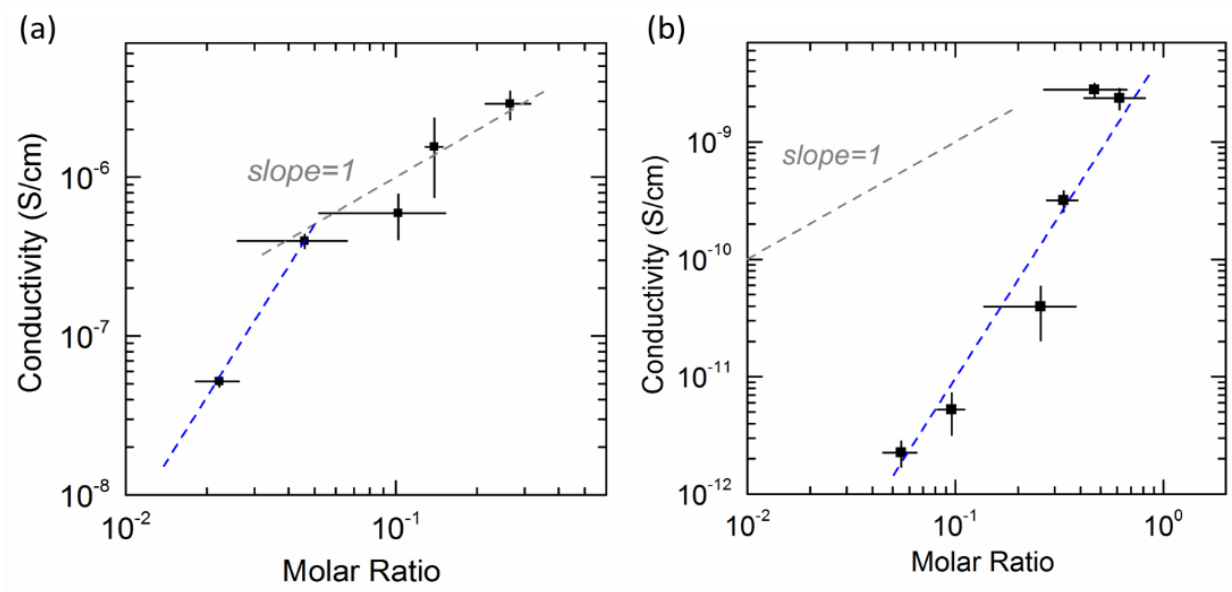

Figure 3. Experimental results for the conductivity of a (a) NPB layer and (b) $\mathrm{Alq}_{3}$ layer as a function of molecular doping ratios with $\mathrm{MoO}_{3}$. The simple linear fitted lines are also given both in Figure (a) and (b). In Figure (b), a line with a slope of unity is given as guide for the eye. 
To further clarify the difference in doped n-type $\mathrm{Alq}_{3}$ films and p-type NPB films, we extract the conductivities from Figure 2 in different $\mathrm{MoO}_{3}$ doped organic films, in which the values are determined at low electric fields from the Ohmic region of the current density- applied voltage scans (from dash lines in Figure 2) [23]. Figure 3 shows experimental data for the conductivity as a function of different MR of $\mathrm{MoO}_{3}$ in (a) NPB films and (b) in $\mathrm{Alq}_{3}$ films. We can clearly find that the conductivities increase with the $\mathrm{MoO}_{3} \mathrm{MR}$ both in NPB and $\mathrm{Alq}_{3}$ films. However, the differences can be also found, where in Figure 3 (a) of p-type NPB films, conductivity increases rapidly at the low doping ratio (MR $<\sim 0.04$ with a slope $S>1$ ) and becomes slower at $M R>\sim 0.04$ with a simple linear fitting by a slope $S \approx 1$; while in Figure 3 (b) of n-type $\mathrm{Alq}_{3}$ films, conductivity rapidly increases within the entire doping range by given a simple fitting with a slope $S>1$. Considering previous studies from S. Olthof et.al, they found the slope changes of the conductivity versus MR in $\mathrm{C}_{60}$ films is due to the initial passivation of unoccupied density of gap states (DOGS) in $\mathrm{C}_{60}$ films via charge transfer and becomes to a slope $S \sim 1$ after completely passivation process. [23] Thus, the initial passivation of occupied DOGS at low doping ratio and generated free holes after passivation can be also reasonably explained in $\mathrm{MoO}_{3}$ doped p-type NPB films. On the other hand, in n-type $\mathrm{Alq}_{3}$ films, a larger slope with $S>1$ occurs in the entire MR region indicates the uncompleted passivation on occupied DOGS, probably due to their larger amounts.

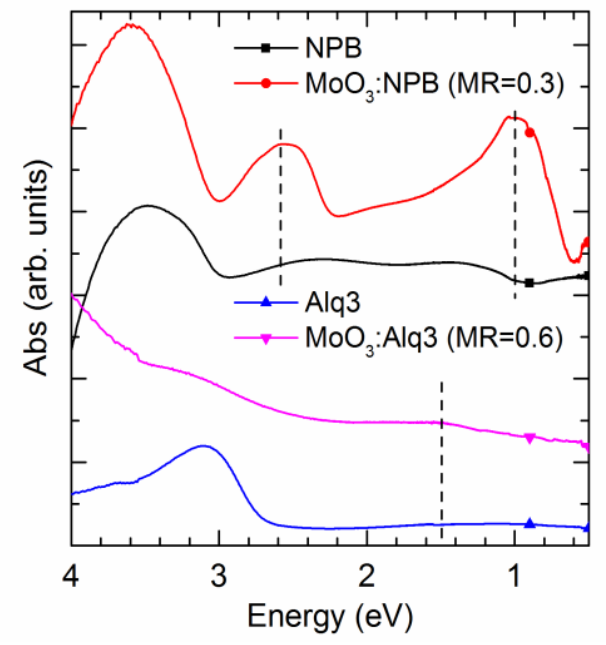

Figure 4. UV-vis absorption spectra of thermally evaporated NPB; $\mathrm{MoO}_{3}$-doped-NPB $\left(\mathrm{MoO}_{3}: \mathrm{NPB}\right)$;

$\mathrm{Alq}_{3}$ and $\mathrm{MoO}_{3}$-doped-Alq $3\left(\mathrm{MoO}_{3}: \mathrm{Alq}_{3}\right)$ on glass substrates .

To confirm the charge transfer induced DOGS passivation can be realized in both of $\mathrm{MoO}_{3}$-dope-NPB films and $\mathrm{MoO}_{3}$-doped-Alq ${ }_{3}$ films, the absorption spectrum of $\mathrm{MoO}_{3}$ doped with NPB films ( $\mathrm{MR}=0.3)$ and $\mathrm{MoO}_{3}$ doped with $\mathrm{Alq}_{3}$ films $(\mathrm{MR}=0.6)$ are shown in Figure 4. Pristine NPB films and $\mathrm{Alq}_{3}$ films are also shown as references. In Figure 4, the peaks at energy position of $3.5 \mathrm{eV}$ and $3.1 \mathrm{eV}$ represent the pristine $\mathrm{NPB}$ and $\mathrm{Alq}_{3}$ absorption energy, respectively, which are consistent to pervious reports. [24, 25] However, additional peaks below pristine absorption energy are shown after doping with two peaks of positions at $2.6 \mathrm{eV}$ and $1.0 \mathrm{eV}$ for $\mathrm{MoO}_{3}$-doped NPB films, and one peak position of $1.5 \mathrm{eV}$ for $\mathrm{MoO}_{3}$-doped-Alq 3 films, which indicate the formation of charge transfer complexes. [26] Considering the energy diagrams of $\mathrm{MoO}_{3}, \mathrm{NPB}$ and $\mathrm{Alq}_{3}$ as shown in Figure 1(b), charge transfer is also expected to occur from HOMO of NPB (and $\mathrm{Alq}_{3}$ ) to the conduction band of $\mathrm{MoO}_{3}$ due to its larger electron affinity. 
(a) For n-type $\mathrm{Alq}_{3}$ films:
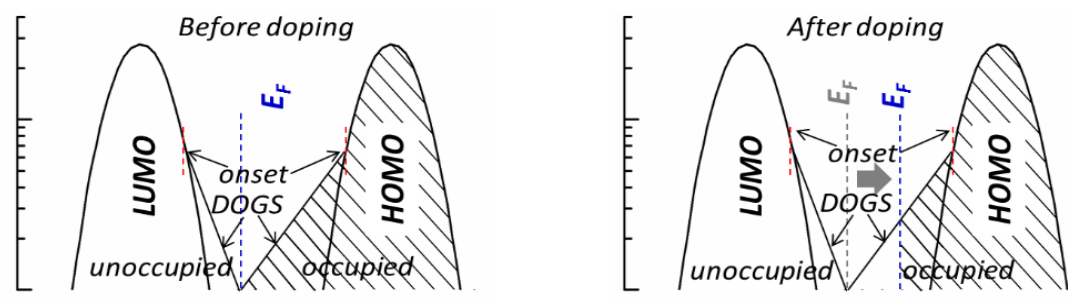

(b) For p-type NPB films:
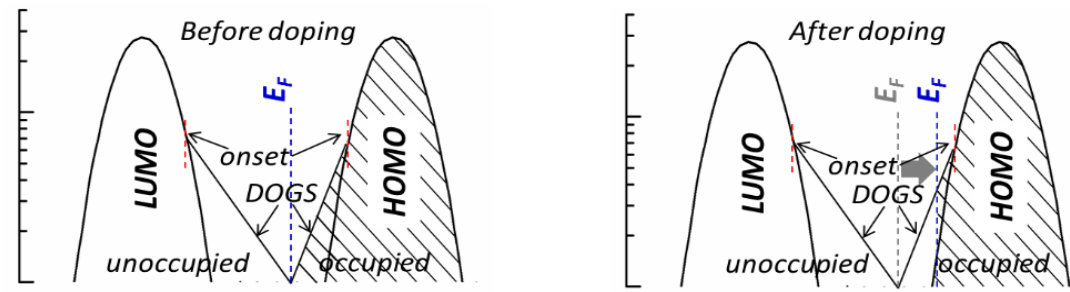

Figure 5. Schematic mechanism of density of gap states (DOGS) in organic films induced "intrinsic" $\mathrm{n}$-/p-type characteristics in (a) n-type $\mathrm{Alq}_{3}$ films before and after $\mathrm{MoO}_{3}$ doping, (b) p-type NPB films before and after $\mathrm{MoO}_{3}$.

Finally, Figure 5 shows the schematic diagrams of elucidating the origin of "intrinsic" n-/p-type organic films and the influence of doping on passivation of DOGS in organic films. It has been pointed out that DOGS induced by structure defects and impurities in pristine organic films give mainly the tailing of LUMO and HOMO into the band gap regions with additional states described either as exponential type or Gaussian type. [27] These DOGS appear in principle via similar mechanism expect their values and energy distributions are not the same, respectively, since the different spatial spreads of HOMO, LUMO and different degeneracies of these states. [28, 29] In "intrinsic" Alq 3 films, the occupied DOGS are much larger than unoccupied DOGS, induce the Fermi level locates much closer to LUMO side, therefore become n-type (the left side of Figure 5(a)). On the contrary, occupied DOGS are much smaller than unoccupied DOGS in NPB films, therefore result in the Fermi level locating closer to HOMO side and making NPB films to be p-type (on the left side of Figure 5 (b)). [30] In n-type films (on the right side of Figure 5(a)), due to much larger amount of occupied DOGS, a high $\mathrm{MoO}_{3} \mathrm{MR}$ is not enough to completely passivate these DOGS, which leading to an effective increase of conductivity with a slope $S>1$. An even higher $\mathrm{MoO}_{3} \mathrm{MR}$ (e.g. 0.61) can then also additionally increase films disordering and therefore increase DOGS in such films, result in a slightly decrease in films conductivity (as shown in Figure 3(b)). However, in p-type films (on the right side of Figure 5(b)), these occupied DOGS can be easily removed by low doping of p-type dopant $\mathrm{MoO}_{3}$, thus demonstrate a rapid increase of the conductivity (as shown in Figure 3(a)). A further increased $\mathrm{MoO}_{3}$ doping then can generate free holes and increase films conductivity with a slope $S \sim 1$.

\section{Conclusion}

In summary, $\mathrm{MoO}_{3}$ as a p-type dopant into "intrinsic" p-type NPB and n-type $\mathrm{Alq}_{3}$ films has been studied via current-voltage measurements and absorption measurements. The conductivities are increased both for NPB films and $\mathrm{Alq}_{3}$ films after $\mathrm{MoO}_{3}$ doping. However, the differences of change of conductivities in NPB films and $\mathrm{Alq}_{3}$ films after doping can be found, where (1) a rapid increase of conductivity in $\mathrm{Alq}_{3}$ with slope $\mathrm{S}>1$ is shown in the entire MR range; (2) in NPB films, the conductivity changes with a slope of $S>1$ can be found in the ultralow doping region $(M R<\sim 0.04)$ and a slope of $\sim 1$ can be found with $\mathrm{MR}>\sim 0.04$. These differences can be well explained from their original different distribution of DOGS in organic films. In n-type $\mathrm{Alq}_{3}$ films, occupied DOGS in n-type films is much larger than unoccupied DOGS, result in doping induced increased conductivity with $S>1$. While in p-type NPB films, due to a smaller amount of occupied DOGS, low doping of 
$\mathrm{MoO}_{3}$ can easily passivate such occupied DOGS, and a further increasing of MR can generate free holes, leading to a slope $\mathrm{S}$ changing from $>1$ to $\sim 1$.

\section{References}

[1] Tang C W and VanSlyke S A, et al. Organic electroluminescent diodes. Appl. Phys. Lett. 51 (1987) 913. p. 913-915.

[2] Uoyama H, Goushi $\mathrm{K}$ and Shizu K, et al. Highly efficient organic light-emitting diodes from delayed fluorescence. Nature 492 (2013) 234. p. 234-238.

[3] He Z, Zhong C and Su S, et al. Ehanced power-conversion efficiency in polymer solar cells using an inverted device structure. Nat. Photonics 6 (2012) 591. p. 591-595.

[4] You J, Dou L and Yoshimura K, et al. A polymer tandem solar cell with $10.6 \%$ power conversion efficiency. Nat. Commun. 4 (2013) 1446. p. 1446

[5] Gershenson M E, Podzorov V, and Morpurgo A F, et al. Electronic transport in single-crystal organic transistors Rev. Mod. Phys. 78 (2006) 973. p. 973-989.

[6] Li H Y, Tee B C K, Cha J J, et al. High-mobility field-effect transistors from large-area solution-grown aligned $\mathrm{C}_{60}$ single crystals. J. Am. Chem. Soc. 134 (2012) 2760. p. 2760-2765.

[7] Braga D. and Horowitz G, et al. High-performance organic field-effect transistors. Adv. Mater. 21 (2009) 1473. p. 1473-1486.

[8] Zaini M S, Mohd Sarjidan M A and Abd. Majid W H, et al. Determination of Traps' Density of State in OLEDs from Current-Voltage Analysis. Chin. Phys. Lett. 33 (2016) 018101. p. 1-5.

[9] Wei C T, Zhuang J Y and Chen Y L, et al. Surface treatment on polyethylenimine interlayer to improve inverted OLED performance Chin. Phys. B 25 (2016) 108505. p. 1-6.

[10] Haddock J N, Zhang X H and Domercq B, Fullerene based n-type organic thin-film transistors. Org. Electron. 6 (2005) 182. p. 182-187.

[11] Kraus M, Richler S and Opitz A, et al. High-mobility copper-phthalocyanine field-effect transistors with tetratetracontane passivation layer and organic metal contacts. J. Appl. Phys. 107 (2010) 094503. p. 1-6.

[12] Zhao J, Cai Y and Yang J P, et al. The role of cesium carbonate on the electron injection and transport enhancement in organic layer by admittance spectroscopy. Appl. Phys. Lett. 101 (2012) 193303. p. 1-4.

[13] Xin L W, Wu X M and Hua Y L, Improvement of electron injection of organic light-emitting devices by inserting a thin aluminum layer into cesium carbonate injection layer. Chin. Phys. B 24 (2015) 037802. p. 1-4.

[14] Tietze M, Burtone L and Riede M, et al. Fermi level shift and doping efficiency in p-doped small molecule organic semiconductors: a photoelectron spectroscopy and theoretical study. Phys. Rev. B. 86 (2012) 035320. p. 1-12.

[15] Pingel P and Neher D, Comprehensive picture of p-type doping of P3HT with the molecular acceptor F4TCNQ. Phys. Rev. B 87 (2013) 115209. p. 1-9.

[16] Yang J P, Wang W Q and Cheng L W, et al. Mechanism for doping induced p type C60 using thermally evaporated molybdenum trioxide (MoO3) as a dopant. J. Phys.: Condens. Matter. 28 (2016)185502. p. 1-6.

[17] Meyer J, Hamwi S and Kroger M, et al. Transition Metal Oxides for Organic Electronics: Energetics, Device Physics and Applications. Adv. Mater. 24 (2012) 5408. p. 5408-5427.

[18] Winkler S, Amsalem P and Frisch J, et al. Probing the energy levels in hole-doped molecular semiconductors. Mater. Horiz. 2 (2015) 427. p. 427-433.

[19] Bussolotti F, Kera S and Kudo K, et al. Potassium doping of single crystalline pentacene thin film. Phys. Rev. Lett. 110 (2013) 267602. p. 1-9.

[20] Sueyoshi T, Kakuta H and Ono M, et al. Band gap states of copper phthalocyanine thin films induced by nitrogen exposure. Appl. Phys. Lett. 96 (2010) 093303. p. 1-3. 
[21] Lee H, Lee $\mathbf{J}$ and Park $S$, et al. Hole injection enhancement of a single-walled carbon nanotube anode using an organic charge-generation layer. Carbon, 71 (2014) 268. p. 268-275.

[22] Bao Q Y, Yang J P and Tang J X, et al. Interfacial electronic structures of WO3-based intermediate connectors in tandem organic light-emitting diodes. Org. Electron. 11 (2010) 1578. p. 1578-1583.

[23] Olthof S, Mehraeen S and Swagat K,et al. Ultralow Doping in Organic Semiconductors: Evidence of Trap Filling. Phys. Rev. Lett. 109 (2012) 176601. p. 1-5.

[24] Chan C Y H, Chow C M and So S K,et al. Using transistor technique to study the effects of transition metal oxide dopants on organic charge transporters. Org. Electron. 12 (2011) 1455. p. 1454-1458.

[25] Cheng C H, Wang $\mathrm{J}$ and $\mathrm{Du} \mathrm{Z} \mathrm{J}$, et al. $1.53 \mu \mathrm{m}$ electroluminescence from ErF3-doped organic light-emitting diodes. Journal of Luminescence. 130 (2010) 2293. p. 2293-2297.

[26] Shin W J, Lee J Y and Kim J C, et al. Bulk and interface properties of molybdenum trioxide-doped hole transporting layer in organic light-emitting diodes. Org. Electron. 9 (2008) 333.p. 333-338.

[27] Mehraeen S, Coropceanu V and Bredas J L. Role of band states and trap states in the electrical properties of organic semiconductors: Hopping versus mobility edge model. Phys. Rev. B 87 (2013) 195209. p. 1-9.

[28] Kang J H, Filho D D S and Bredas J L, et al. Shallow trap states in pentacene thin films from molecular sliding. Appl. Phys. Lett. 86 (2005) 152115. p. 1-3.

[29] Zhong J Q, Mao H Y and Wang R, et al. Ionization potential dependent air exposure effect on the MoO3/organic interface energy level alignment. Org. Electron. 13 (2012) 2793. p. 2793-2800.

[30] Yang J P, Sun Q J and Yonezawa K,et al. Interface optimization using diindenoperylene for C60 thin film transistors with high electron mobility and stability. Org. Electron. 15 (2014) 2749. p. 2749-2755. 